\title{
An update to the Tachinidae fauna of Croatia (Diptera)
}

\author{
Erikas Lutovinovas, Miroslav Barták, Bože Kokan \& Roman Ozimec
}

Lutovinovas, E., Barták, M., Kokan, B. \& Ozimec, R. 2018: An update to the Tachinidae fauna of Croatia (Diptera). — Entomol. Fennica 29: 54-60.

This paper updates the Tachinidae fauna of Croatia. We report 50 species for the first time for Croatia and six of these are new records for the Balkan Peninsula: Chetogena micronychia, Istocheta subcinerea, Meigenia simplex, Leucostoma edentatum, Peribaea discicornis and P. longirostris.

E. Lutovinovas, Nature Research Centre, Akademijos 2, LT-08412 Vilnius, Lithuania; E-mails: wohlfahrtia@gmail.com, erikas.lutovinovas@gamtostyrimai.lt

M. Barták, Department of Zoology and Fisheries, Faculty of Agrobiology, Food and Natural Resources, Czech University of Life Sciences, Kamýcká 129, CZ16521 Praha, The Czech Republic; E-mail: bartak@af.czu.cz

B. Kokan, Natural History Museum and Zoo, Kolombatovićevo šetalište 2, HR21000 Split, Croatia; E-mail: boze@prirodoslovni.hr

R. Ozimec, ADIPA - Croatian Society for Natural History Diversity Research \& Conservation, Orehovečki ogranak 37, HR-10040 Zagreb, Croatia; E-mail: ozimec.roman@gmail.com

Received 26 March 2017, accepted 14 July 2017

\section{Introduction}

Tachinid flies are one of the largest families in the order Diptera and distinctly the largest group of the Calyptrata section (Tschorsnig \& Richter 1998). Some of these insects are black, tiny and rarely seen in nature, while others are bright, large, and easily spotted in the field. The basic food requirements tachinids consume in the larval stage, but their adults, when visiting flowers, play a role as pollinators of some plants (Tooker et al. 2006, Al-Dobai et al. 2012). All known species of tachinids develop as obligate endoparasitoids in many insect host orders (predominantly moth caterpillars, but also sawfly larvae, beetle larvae and adults, crane fly larvae, bugs, etc.) and terrestrial noninsect arthropods (specifically centipedes and scorpions), and as such have a great ecological importance (Stireman et al. 2006). Accordingly, the tachinids as a family have associations with wide range of hosts, but certain groups of tachinids have more specialized associations. However, not just diversity of hosts in the habitat, but also habitat connectivity that enables parasitoid spillover and other ecological factors determine diversity of tachinids (Stireman 2008, Inclán et al. 2014). Most tachinids are thermophilic, and the fauna of Southern Europe is therefore richer than that of Central Europe, where tachinids have been thoroughly studied (Tschorsnig \& Herting 1994). There are also some species that have expanded their distribution to the north due to global warming (Zeegers 2010, Ziegler 2011). However, the fauna of several southeastern European countries remains relatively unknown and requires further investigation.

The most up-to-date checklist of Tachinidae 
of the Balkan countries (Hubenov 2008a) lists 241 species for the fauna of Croatia. Croatia is a country that boasts a spectacular landscape and many rare habitats, and due to its specific geographical position that cover four biogeographical regions (Pannonian, Continental, Alpine and Mediterranean), it is possibly one of the richest European country in terms of biodiversity (Radović et al. 2009).

The aim of the present publication is to enrich knowledge of the Tachinidae fauna of Croatia by adding new faunistic records.

\section{Materials and methods}

The majority of the material originates from Gornji Muć (Fig. 1) and was collected in seasons of 2013 and 2014 using a modified Townes type Malaise trap (with a broader and higher "roof"). The trap was operated by the third author of this report (B. Kokan), and sorting of the material was carried out by the second author (M. Barták). Single specimens originating from other localities were collected by M. Barták in 2007; these specimens were sampled using a conventional entomological net.

After being preserved in ethanol (70\%), all specimens were mounted dry using a method described by Barták (1997). With the exception of a duplicate specimen of Chetogena micronychia, which is deposited in the Stuttgart State Museum of Natural History (SMNS), all voucher specimens are deposited in the insect collection at the Czech University of Life Sciences Prague (CULSP). Full names of the localities are presented next to each recorded species while their coordinates and collectors are in Table 1.

The material was identified by the first author of this report (E. Lutovinovas). Species were identified in accordance to Cerretti (2010), but we also consulted Mesnil (1944-1975), Herting

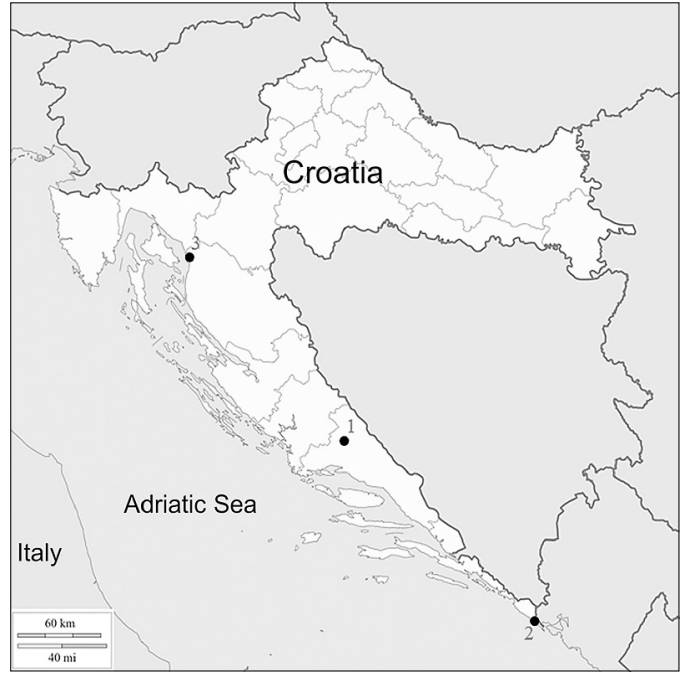

Fig. 1. Map of Croatia, showing studied localities. For numbering of localities, see Table 1.

(1983) as well as Cerretti and Tschorsnig (2008). Taxonomy of the species and their general distributions were acquired primarily from Herting and Dely-Draskovits (1993), but we also utilized other reference sources (Doğanlar 1982a, b, Draber-Mońko 1993, Andersen 1996, Tschorsnig \& Herting 1998, Zeegers 1998, Kara \& Alaoğlu 1999, Cerretti \& Ziegler 2004, Vaňhara et al. 2004, Ostovan \& Gheibi 2008, O'Hara et al. 2009, Cerretti 2010, Lutovinovas 2012, Gilasian et al. 2014a, b, Pohjoismäki \& Kahanpää 2014). The species are listed alphabetically within each subfamily, which was done to avoid tribal division.

\section{Results}

Below, the 50 species new to Croatia are listed with those new for the whole Balkan Peninsula marked with an asterisk $(*)$.

Table 1. Details of sampling locations with collectors of Tachinidae in Croatia.

\begin{tabular}{|c|c|c|c|c|c|}
\hline No. & Locality & Altitude & County & Coordinate & Collector \\
\hline 1 & Gornji Muć & $500 \mathrm{~m}$ & Split & $43^{\circ} 41^{\prime} 27^{\prime \prime} \mathrm{N} 16^{\circ} 29^{\prime} 44^{\prime \prime} \mathrm{E}$ & B. Kokan \\
\hline 2 & Molunat & $150 \mathrm{~m}$ & Dubrovnik & $42^{\circ} 28^{\prime} 52^{\prime \prime} \mathrm{N} 18^{\circ} 25^{\prime} 57^{\prime \prime E}$ & M. Barták \\
\hline 3 & Senj & seashore & Lika & $44^{\circ} 58^{\prime} 26^{\prime \prime} \mathrm{N} 14^{\circ} 55^{\prime} 13^{\prime \prime} \mathrm{E}$ & M. Barták \\
\hline
\end{tabular}




\subsection{Subfamily Dexiinae}

Blepharomyia pagana (Meigen, 1824). - Material: Gornji Muć, 11.IV.-10.V.2014, 2ðึે, $2 \uparrow ᄋ$. - Distribution: all Europe northwards to Scotland and Lapland; Transcaucasia, S. Siberia (Herting \& Dely-Draskovits 1993).

Campylocheta inepta (Meigen, 1824). - Material: Gornji Muć, 24.V.-28.VI.2014, 1§; 29.VI.-20.VII.2014, 1ठ; 15.-28.IX.2014, 1․ - Distribution: all Europe northwards to Scotland and Finland; Transcaucasia, S. Siberia (Herting \& Dely-Draskovits 1993, Pohjoismäki \& Kahanpää 2014).

Campylocheta latigena Mesnil, 1974. - Material:

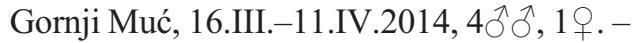
Distribution: Europe northwards to France and the Czech Rep. (Herting \& DelyDraskovits 1993, Vaňhara et al. 2004).

Estheria picta (Meigen, 1826). - Material: Gornji Muć, 28.VII.-11.VIII.2013, 1․ - Distribution: Europe northwards to the Netherlands and vicinity of St. Petersburg; Transcaucasia, Kazakhstan, S. Siberia, Mongolia (Herting \& Dely-Draskovits 1993, Zeegers 1998).

Stomina tachinoides (Fallén, 1817). - Material: Gornji Muć, 24.VIII.-14.IX.2014, 2ðึో. Distribution: Europe northwards to C. Sweden and Finland; Palestine, Mongolia, China (Herting \& Dely-Draskovits 1993, O'Hara et al. 2009, Pohjoismäki \& Kahanpää 2014).

\subsection{Subfamily Phasiinae}

Catharosia flavicornis (Zetterstedt, 1859). - Ma-

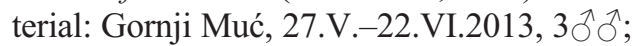
22.VI.-28.VII.2013, 1ठ; 11.VIII.15.IX.2013, 1ð, 2웅.--Distribution: Europe northwards to France and S. Poland; Palestine, S. Siberia (Herting \& Dely-Draskovits 1993).

Clytiomya mesnili Kugler, 1968. - Material: Senj, 18.V.2007, 1ठ․ - Distribution: S. Europe; Israel (Herting \& Dely-Draskovits 1993).

Cylindromyia crassa (Loew, 1845). - Material: Gornji Muć, 22.VI.-13.VII.2013, 1ㅇ․ Distribution: S. Europe northwards to Hungary; Palestine, Transcaucasia, Iran, S. Sibe- ria (Herting \& Dely-Draskovits 1993, Gilasian et al. 2014b).

Cylindromyia xylotina (Egger, 1860). - Material: Gornji Muć, 27.V.-22.VI.2013, 19. - Distribution: Europe northwards to S. Germany and the Czech Rep. (Herting \& Dely-Draskovits 1993, Vaňhara et al. 2004).

Labigastera nitidula (Meigen, 1824). - Material: Gornji Muć, 22.VI.-13.VII.2013, 1q; 08.28.VI.2014, 1ठ․ - Distribution: S. Europe northwards to Switzerland; Algeria, Palestine (Herting \& Dely-Draskovits 1993).

Labigastera pauciseta (Rondani, 1861). - Material: Gornji Muć, 27.V.-22.VI.2013, 1q; 29.VI.-20.VII.2014, 19. - Distribution: Europe northwards to $\mathrm{S}$. Germany and the Czech Rep.; Turkey, Iran (Herting \& DelyDraskovits 1993, Kara \& Alaoğlu 1999, Vaňhara et al. 2004, Gilasian et al. 2014a).

Leucostoma anthracinum (Meigen, 1824). - Material: Gornji Muć, 27.V.-11.VIII.2013,

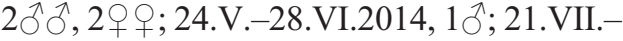
10.VIII.2014, 1․ - Distribution: Europe northwards to Germany and vicinity of St. Petersburg; Transcaucasia, S. Siberia, Mongolia (Herting \& Dely-Draskovits 1993).

*Leucostoma edentatum Kugler, 1978. - Material: Gornji Muć, 24.VIII.-14.IX.2014, 1․ Distribution: reported from Italy; Israel (Herting \& Dely-Draskovits 1993, Cerretti 2010).

Leucostoma tetraptera (Meigen, 1824). - Material: Gornji Muć, 27.V.-22.VI.2013, 1ð’; 22.VI.-28.VII.2013, $3 \circ \circ$; 28.VII.-11.VIII. 2013, 1; 24.VIII.-14.IX.2014, 1 ․ - - Distribution: Europe northwards to France and the Czech Rep.; Morocco, Transcaucasia, S. Siberia (Herting \& Dely-Draskovits 1993, Vaňhara et al. 2004).

Leucostoma turonicum Dupuis, 1964. - Material: Gornji Muć, 27.V.-22.VI.2013, 1§, 1; 22.VI.-28.VII.2013，3ㅇ；29.VI.-20.VII. 2014, 1q; 21.VII.-10.VIII.2014, 1q; 10.24.VIII.2014, 2qo; 24.VIII.-14.IX.2014, 1․ - Distribution: Europe northwards to France and Slovakia (Herting \& DelyDraskovits 1993).

Phania curvicauda (Fallén, 1820). - Material: Gornji Muć, 27.V.-22.VI.2013, 1q. - Distribution: Europe northwards to C. Sweden and 
Finland (Herting \& Dely-Draskovits 1993, Pohjoismäki \& Kahanpää 2014).

\subsection{Subfamily Tachininae}

Actia infantula (Zetterstedt, 1844). - Material: Gornji Muć, 27.V.-22.VI.2013, 10;; 29.VI.20.VII.2014, 1ठ; 21.VII.-10.VIII.2014, $1 \delta^{\lambda}$. - Distribution: all Europe northwards to England and Finland; Morocco, Tunisia, Palestine, Transcaucasia, S. Siberia (Herting \& Dely-Draskovits 1993, Andersen 1996, Pohjoismäki \& Kahanpää 2014).

Ceromya flaviseta (Villeneuve, 1921). - Material: Gornji Muć, 10.-24.VIII.2014, 2ふふ઼. Distribution: Europe northwards to Denmark and Poland; China (Draber-Mońko 1993, Herting \& Dely-Draskovits 1993, Andersen 1996, O'Hara et al. 2009).

Macquartia tessellum (Meigen, 1824). - Mate-

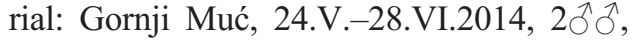
5웅. - Distribution: Europe northwards to Switzerland and Slovakia; Canary Is., Palestine, Turkey, Transcaucasia, Iran, Tadjikistan, China; Oriental Region (Doğanlar 1982b, Herting \& Dely-Draskovits 1993, Ostovan \& Gheibi 2008, O’Hara et al. 2009).

Pelamera atra (Rondani, 1861). - Material: Gornji Muć, 27.IV.-10.V.2014, 19 . - Distribution: reported from Italy, Switzerland and Greece (Herting \& Dely-Draskovits 1993, Cerretti \& Ziegler 2004).

* Peribaea discicornis (Pandellé, 1894). - Material: Gornji Muć, 27.IV.-23.V.2014, 1ठ; 29.VI.-20.VII.2014，1今゙; 10.-24.VIII.2014, 1ठิ. - Distribution: S. Europe northwards to Switzerland; Tunisia (Herting \& DelyDraskovits 1993, Andersen 1996).

* Peribaea longirostris Andersen, 1996. - Material: Gornji Muć, 22.VI.-28.VII.2013, 10; 08.-28.VI.2014, 1今. - Distribution: Europe northwards to the Netherlands and Finland (Andersen 1996, Zeegers 1998, Lutovinovas 2012, Pohjoismäki \& Kahanpää 2014).

Plesina claripennis Mesnil, 1953. - Material: Gornji Muć, 11.VIII.-15.IX.2013, 1․ Distribution: reported from Greece; Palestine (Cerretti \& Tschorsnig 2008, Zeegers 2017). Siphona pauciseta Rondani, 1865. - Material:
Gornji Muć, 28.VII.-11.VIII.2013, 1\%; 11.VIII.-15.IX.2013，1\%; 08.-28.VI.2014, 1ठ․ - Distribution: all Europe northwards to England and Finland; S. Siberia, Mongolia, China, Kuril Is. (Herting \& Dely-Draskovits 1993, Andersen 1996, O’Hara et al. 2009).

Triarthria setipennis (Fallén, 1810). - Material: Gornji Muć, 16.III.-26.IV.2014, 10̄; 27.IV.23.V.2014, 1ð; 24.V.-28.VI.2014, 3우; 15.-28.IX.2014, 1․ - - Distribution: all Europe northwards to Scotland and Finland; Palestine, Transcaucasia (Herting \& DelyDraskovits 1993, Pohjoismäki \& Kahanpää 2014).

Ziminia masiceraeformis (Portshinsky, 1881). Material: Gornji Muć, 27.V.-22.VI.2013,

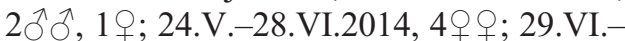
20.VII.2014, 2 q + ; 29.IX.-10.X.2014, 1 ․ Distribution: S. Europe northwards to Switzerland; Israel, Transcaucasia, Tadjikistan (Herting \& Dely-Draskovits 1993).

\subsection{Subfamily Exoristinae}

Atylomyia loewii Brauer, 1898. - Material: Gornji Muć, 29.VI.-20.VII.2014, 19. Distribution: Europe northwards to Lithuania; Israel, S. Siberia, Mongolia (Herting \& Dely-Draskovits 1993, Lutovinovas 2012).

Blondelia nigripes (Fallén, 1810). - Material: Gornji Muć, 10.-24.VIII.2014, 1§̂. - Distribution: all Europe northwards to England and N. Sweden; Transcaucasia, C. Asia, S. Siberia, Mongolia, China, Japan, Kuril Is. (Herting \& Dely-Draskovits 1993, O’Hara et al. 2009).

Brachicheta strigata (Meigen, 1824). - Material: Gornji Muć, 16.III.-11.IV.2014, 1․ Distribution: all Europe northwards to Scotland and Finland; Transcaucasia (Herting \& Dely-Draskovits 1993, Pohjoismäki \& Kahanpää 2014).

Cadurcia casta (Rondani, 1861). - Material: Gornji Muć, 29.VI.-20.VII.2014, 1․ Distribution: S. Europe; Turkey, Transcaucasia (Herting \& Dely-Draskovits 1993).

Ceratochaetops delphinensis (Villeneuve, 1931). - Material: Gornji Muć, 27.V.-22.VI.2013, 19. - Distribution: reported from France, 
Greece; S. Siberia, Mongolia (Herting \& Dely-Draskovits 1993, Cerretti \& Ziegler 2004).

Chetina setigena (Rondani, 1856). - Material: Gornji Muć, 27.V.-22.VI.2013, 3ठิðَ, 5우; 22.VI.-28.VII.2013, 2ðえ, 9우; 28.VII.11.VIII.2013, 1ð, 6 우; 11 .VIII.15.IX.2013, 2우; 24.V.-28.VI.2014，1ठో; 29.VI.-20.VII.2014, 1今; 21. VII.10.VIII.2014，8우; 24.VIII.-14.IX.2014, 2 ㅇ‥ - Distribution: S. Europe northwards to C. France; Israel, Transcaucasia, Turkmenia, Tajikistan (Herting \& Dely-Draskovits 1993).

*Chetogena micronychia (Masson, 1969). - Material: Gornji Muć, 27.V.-22.VI.2013, $3 \delta^{\Uparrow}$, 2우; 22.VI.-28.VII.2013，9ふえ, 7우; 28.VII.-11.VIII.2013, 2 ふ઼, $3 \circ$ ○; 11.VIII.15.IX.2013, 2우; 15.IX.-06.X.2013, 19; 24.V.-28.VI.2014, 1क; 29.VI.-20.VII.2014, 2우; 21.VII.-10.VIII.2014, 1․ - - Distribution: reported from France and Italy (Herting \& Dely-Draskovits 1993, Inclán 2016).

Eumea linearicornis (Zetterstedt, 1844). - Material: Molunat, 21.V.2007, 1․ - - Distribution: all Europe northwards to England and Finland; Transcaucasia, S. Siberia, China, Japan, Kuril Is. (Herting \& Dely-Draskovits 1993, O’Hara et al. 2009, Pohjoismäki \& Kahanpää 2014).

*Istocheta subcinerea (Borisova-Zinoveva, 1966). - Material: Gornji Muć, 22.VI.13.VII.2013, 1; 27.IV.-10.V.2014, 1․ Distribution: reported from Italy and Ukraine; S. Siberia (Herting \& Dely-Draskovits 1993, Cerretti 2010, Pohjoismäki \& Kahanpää 2014).

Ligeria angusticornis (Loew, 1847). - Material: Gornji Muć, 28.VII.-11.VIII.2013, 2우웅 11.VIII.-15.IX.2013, 2우. - Distribution: all Europe northwards to England and Finland; Palestine, Transcaucasia, S. Siberia (Herting \& Dely-Draskovits 1993, Pohjoismäki \& Kahanpää 2014).

Ligeriella aristata (Villeneuve, 1911). - Material: Gornji Muć, 08.-28.VI.2014, 1ठ․ Distribution: Europe northwards to Finland; Tadjikistan, Mongolia, China (Herting \& Dely-Draskovits 1993, O'Hara et al. 2009, Pohjoismäki \& Kahanpää 2014).
Lomachantha parra Rondani, 1859. - Material: Gornji Muć, 21.VII.-10.VIII.2014, 1․ Distribution: Europe northwards to Germany and Slovakia; Transcaucasia, Uzbekistan (Herting \& Dely-Draskovits 1993).

Lydella grisescens Robineau-Desvoidy, 1830. Material: Senj, 18.V.2007, 10. - Distribution: Europe northwards to England and Germany; Israel, Transcaucasia, Tadjikistan, Mongolia, S. Siberia, China (Herting \& DelyDraskovits 1993, O'Hara et al. 2009).

Medina collaris (Fallén, 1820). - Material: Gornji Muć, 24.V.-28.VI.2014, 19; 24.VIII.-14.IX.2014, 1 9. - Distribution: all Europe northwards to Scotland and Finland; Transcaucasia, Mongolia, S. Siberia, China, Kuril Is. (Herting \& Dely-Draskovits 1993, O’Hara et al. 2009, Pohjoismäki \& Kahanpää 2014).

*Meigenia simplex Tschorsnig \& Herting, 1998. - Material: Senj, 18.V.2007, 1ठ․ - Distribution: S. Europe northwards to Switzerland; Turkey (Tschorsnig \& Herting 1998).

Oswaldia spectabilis (Meigen, 1824). - Material: Gornji Muć, 21.VII.-10.VIII.2014, 1․ Distribution: Europe northwards to C. Sweden and Finland; Transcaucasia (Herting \& Dely-Draskovits 1993, Pohjoismäki \& Kahanpää 2014).

Pales pumicata (Meigen, 1824). - Material: Gornji Muć, 24.V.-08.VI.2014, 1 9 . - Distribution: S. Europe northwards to Switzerland (Herting \& Dely-Draskovits 1993).

Paratryphera barbatula (Rondani, 1859). - Material: Gornji Muć, 28.VII.-11.VIII.2013, 2우; 11.VIII.-15.IX.2013, 1; 29.VI.20.VII.2014, 19. - Distribution: Europe northwards to Finland; Israel, Transcaucasia, S. Siberia, Mongolia, China, Japan, Kuril Is. (Herting \& Dely-Draskovits 1993, O’Hara et al. 2009, Pohjoismäki \& Kahanpää 2014).

Paratryphera bisetosa (Brauer \& Bergenstamm, 1891). - Material: Gornji Muć, 24.VIII.14.IX.2014, 1ㅇ. - Distribution: Europe northwards to Switzerland and Slovakia; China, Japan (Herting \& Dely-Draskovits 1993, Vaňhara et al. 2004, O’Hara et al. 2009).

Phryno vetula (Meigen, 1824). - Material: Gornji Muć, 11.-27.IV.2014, 1ठ․ - Distribution: 
Europe northwards to England and Denmark; Turkey, Transcaucasia, S. Siberia, China (Doğanlar 1982a, Herting \& Dely-Draskovits 1993, O'Hara et al. 2009).

Phryxe magnicornis (Zetterstedt, 1838). - Mate-

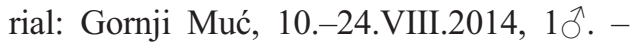
Distribution: all Europe northwards to Scotland and Finland; Transcaucasia, S. Siberia, Mongolia, China, Kuril Is. (Herting \& DelyDraskovits 1993, O'Hara et al. 2009, Pohjoismäki \& Kahanpää 2014).

Platymya fimbriata (Meigen, 1824). - Material: Gornji Muć, 27.V.-22.VI.2013, 4ㅇ; 24.V.08.VI.2014, 1․ - Distribution: all Europe northwards to England and Lapland; Israel, Transcaucasia, C. Asia, S. Siberia, Mongolia, China, Kuril Is. (Herting \& Dely-Draskovits 1993, O’Hara et al. 2009).

Smidtia amoena (Meigen, 1824). - Material: Gornji Muć, 10.-24.V.2014, 1ㅇ. - Distribution: all Europe northwards to England and Finland; Transcaucasia, Kazakhstan, Tadjikistan, S. Siberia, China, Japan (Herting \& Dely-Draskovits 1993, O’Hara et al. 2009, Pohjoismäki \& Kahanpää 2014).

Thecocarcelia acutangulata (Macquart, 1850). Material: Gornji Muć, 27.V.-22.VI.2013, 19. - Distribution: Europe northwards to the Netherlands and the Czech Rep.; Transcaucasia, Japan (Herting \& Dely-Draskovits 1993, Vaňhara et al. 2004, Zeegers 2010).

\section{Discussion}

Hubenov (2008a) listed 241 species for the fauna of Croatia, which is certainly an incomplete representation of the real fauna, when numbers of known species from neighbouring countries are taken into account. The tachinid fauna of Croatia is perhaps two-fold. In the present study, 50 species were recorded for the first time for Croatia, increasing the known fauna of this country to 291 species. Our list includes many species that are considered common all over Europe (e.g. Blondelia nigripes, Medina collaris, Triarthria setipennis), but we also detected some rarely recorded species, registered from fewer countries (e.g. Ceratochaetops delphinensis, Pelamera atra, Plesina claripennis), which have been re- ported only from Greece among the Balkan countries (Cerretti \& Ziegler 2004, Zeegers 2017). Hubenov (2008a) noted that the known tachinid fauna of Croatia is most similar to that of Greece among the Balkan contries, which is also demonstrated in this publication by the unique records common with Greece.

Among the new records for Croatia, the following six species were newly recorded also for the Balkan Peninsula: Chetogena micronychia, Istocheta subcinerea, Meigenia simplex, Leucostoma edentatum, Peribaea discicornis and P. longirostris. Adding these records, 614 species in total are known from the Balkan countries (Hubenov 2008a, b, Ziegler 2010, Pohjoismäki et al. 2016, Zeegers 2017). However, this is still an incomplete number of the Balkan species as there are some unpublished records (H.-P. Tschorsnig, pers. comm.).

Acknowledgements. We thank H.-P. Tschorsnig (Stuttgart) for the confirmation of several species. This paper was supported by S-grant of MSMT-CZ (Ministry of Education, Sports and Youth of the Czech Republic, for M. Barták).

\section{References}

Al-Dobai, S., Reitz, S. \& Sivinski, J. 2012: Tachinidae (Diptera) associated with flowering plants: estimating floral attractiveness. - Biological Control 61: 230 239.

Andersen, S. 1996: The Siphonini (Diptera: Tachinidae) of Europe. - Fauna Entomologica Scandinavica 33: 1148.

Barták, M. 1997: The biomonitoring of Diptera by means of yellow pan water traps. - Folia Facultatis Scientiarium Naturalis Universita Masarykianae Brunensis, Biologia 95: 9-16.

Cerretti, P. 2010: I tachinidi della fauna italiana (Diptera Tachinidae), con chiave interattiva dei generi ovestpaleartici. 2 volumes, $573+339$ pp. - Centro Nazionale Biodiversitá Forestale, Cierre Edizioni, Verona.

Cerretti, P. \& Ziegler, J. 2004: Chorologic data on tachinid flies from mainland Greece (Diptera, Tachinidae). Fragmenta Entomologica 362: 275-317.

Cerretti, P. \& Tschorsnig, H.-P. 2008: A new species of Plesina Meigen (Diptera: Tachinidae) from the Mediterranean. - Stuttgarter Beiträge zur Naturkunde A, Neue Serie 1: 445-450.

Doğanlar, M. 1982a: Some parasitoid flies founded in east Anatolia I. (Diptera: Tachinidae: Exoristinae). Türkiye Bitki Koruma Dergisi 6: 161-173. [In Turkish.] 
Doğanlar, M. 1982b: Some parasitoid flies founded in east Anatolia II. Echinomyiinae, Dexiinae, Phasiinae (Diptera: Tachinidae). — Türkiye Bitki Koruma Dergisi 6: 209-220 [In Turkish.]

Draber-Mońko, A. 1993: Tachinid flies (Tachinidae, Diptera) of the Świętokrzyski Region. - Fragmenta Faunistica 36: 275-328. [In Polish.]

Gilasian, E., Talebi, A. A., Ziegler, J. \& Manzari, S. 2014a: Taxonomic study of the tribe Leucostomatini (Dip.: Tachinidae: Phasiinae) in Iran. - Journal of Entomological Society of Iran 34(1): 35-58. [In Persian.]

Gilasian, E., Talebi, A. A., Ziegler, J., Manzari, S. \& Parchemi-Araghi, M. 2014b: A review of the genus $C y$ lindromyia Meigen (Diptera: Tachinidae) in Iran, with the description of two new species and the newly discovered male of $C$. persica Tschorsnig. - Studia Dipterologica 20(2): 299-324.

Herting, B. 1983: Phasiinae. — In: Lindner, E. (ed.), Die Fliegen der palaearktischen Region 9: 1-88.

Herting, B. \& Dely-Draskovits, A. 1993: Family Tachinidae. - In: Soós, A. \& Papp, L. (eds), Catalogue of Palaearctic Diptera 13: 118-624.

Hubenov, Z. 2008a: Composition and Zoogeographical characteristics of the family Tachinidae (Insecta: Diptera) in the Balkan countries. - Acta Zoologica Bulgarica 60(3): 243-265.

Hubenov, Z. 2008b: Composition and zoogeographical characteristics of the family Tachinidae (Diptera: Insecta) in Serbia and Bulgaria. - In: Makarov, S. E. \& Dimitrijević, R. N. (eds), Advances in Arachnology and Developmental Biology 12: 375-394.

Inclán, D. J. 2016: Landscape dynamics of tachinid parasitoids. — In: O'Hara, J. E. (ed.), The Tachinid Times 29: 18-19.

Inclán, D. J., Cerretti, P. \& Marini, L. 2014: Interactive effects of area and connectivity on the diversity of tachinid parasitoids in highly fragmented landscapes. Landscape Ecology 29: 879-889.

Kara, K. \& Alaoğlu, Ö. 1999: Systematic studies on Exoristinae and Phasiinae (Diptera: Tachinida) in Tokat province. - Türkiye 4. Biyolojik Mücadele Kongresi, Adana, Ocak 26-29: 563-586. [In Turkish.]

Lutovinovas, E. 2012: New country and host records for Lithuanian Tachinidae (Diptera). - Entomologica Fennica 23: 231-238.

Mesnil, L. P. 1944-1975: Larvaevorinae (Tachininae). In: Lindner, E. (ed.), Die Fliegen der palaearktischen Region 10(1-3): 1-1435.

O’Hara, J. E., Shima, H. \& Zhang, C.-T. 2009: Annotated Catalogue of the Tachinidae (Insecta: Diptera) of China. - Zootaxa 2190: 1-236.

Ostovan, H. \& Gheibi, M. 2008: Preliminary investigation on the fauna of Tachinid flies (Diptera: Tachinidae) of Fars province, Iran. - Plant Protection Journal 1(2): 140-166. [In Persian.]

Pohjoismäki, J. L. O. \& Kahanpää, J. 2014: Checklist of the superfamilies Oestroidea and Hippoboscoidea of Finland (Insecta, Diptera). - ZooKeys 441: 383-408.
Pohjoismäki, J. L. O, Kahanpää, J. \& Mutanen, M. 2016: DNA Barcodes for the Northern European Tachinid Flies (Diptera: Tachinidae). — PLoS ONE 11(11): e0164933. doi:10.1371/journal. pone.0164933

Radović, J., Čivić, K., Topić, R. \& Vukelić, V. P. (eds) 2006: Biodiversity of Croatia. Second revised edition. - State Institute for Nature Protection Ministry of Culture. Zagreb, Republic of Croatia. 43 pp.

Stireman, J. O. 2008: Alpha and beta diversity of a tachinid parasitoid community over space and time. - Annals of the Entomological Society of America 101: 362 370.

Stireman, J. O., O’Hara, J. E. \& Wood, D. M. 2006: Tachinidae: evolution, behavior, and ecology. - Annual Review of Entomology 51: 525-555.

Tooker, J. F., Hauser, M. \& Hanks, L. M. 2006: Floral host plants of Syrphidae and Tachinidae (Diptera) of Central Illinois. - Annals of the Entomological Society of America 99(1): 96-112.

Tschorsnig, H.-P. \& Herting, B. 1994: Die Raupenfliegen (Diptera: Tachinidae) Mitteleuropas: Bestimmungstabellen und Angaben zur Verbreitung und Ökologie der einzelnen Arten. - Stuttgarter Beiträge zur Naturkunde, Serie A (Biologie) 506: 1-170.

Tschorsnig, H.-P. \& Herting, B. 1998: A new species of the genus Meigenia Robineau-Desvoidy (Diptera: Tachinidae). - Stuttgarter Beiträge zur Naturkunde, Serie A (Biologie) 569: 1-5.

Tschorsnig, H.-P. \& Richter, V. A. 1998: Family Tachinidae. - In: Papp, L. \& Darvas, B. (eds), Contributions to a manual of Palaearctic Diptera (with special reference to flies of economic importance) 3: 691-827.

Vaňhara, J., Tschorsnig, H.-P. \& Barták, M. 2004: New records of Tachinidae (Diptera) from the Czech Republic and Slovakia, with revised checklist. — Studia dipterologica 10: 679-701.

Zeegers, T. 1998: An annotated checklist of the Dutch tachinid flies (Diptera: Tachinidae). —Entomologische Berichten, Amsterdam 58(9): 165-200.

Zeegers, T. 2010: Tweede aanvulling op de naamlijst van Nederlandse sluipvliegen (Diptera: Tachinidae). Nederlandse faunistische mededelingen 34: 55-66. [In Dutch with English summary.]

Zeegers, T. 2017: New and interesting Tachinidae from Greece. - In: O'Hara, J. E. (ed.), The Tachinid Times 30: $21-25$.

Ziegler, J. 2010: Revision of the genus Germaria Robineau-Desvoidy (Diptera, Tachinidae) from Greece, with descriptions of two new species. - Deutsche Entomologische Zeitschrift 57(1): 43-57.

Ziegler, J. 2011: Rezente Arealerweiterungen bei Wanzenfliegen (Diptera: Tachinidae, Phasiinae) in Nordostdeutschland und eine Übersicht zur Gesamtverbreitung von fünf Arten. - Studia dipterologica 18(1/2): 29-54. 